\title{
The annual costs of cardiovascular diseases and mental disorders attributable to job strain in France
}

\author{
Hélène Sultan-Taïeb ${ }^{1,2,3^{*}}$, Jean-François Chastang ${ }^{4,5,6}$, Malika Mansouri ${ }^{3}$ and Isabelle Niedhammer ${ }^{4,5,6}$
}

\begin{abstract}
Background: Work stress has become a major occupational risk factor in industrialized countries and an important economic issue. The objective was to estimate the annual costs of coronary heart diseases (CHD) and mental disorders (MD) attributable to job strain exposure according to Karasek's model in France for the year 2003 from a societal perspective.
\end{abstract}

Methods: We produced attributable fraction estimates which were applied to the number of cases (morbidity and mortality) and the costs of CHD and MD. Relative risk estimates came from a systematic literature review of prospective studies. We conducted meta-analyses based on this selection of studies. Prevalence of exposure to job strain came from the national SUMER survey conducted in France in 2003. Costs included direct medical costs and indirect costs: production losses due to sick leaves and premature deaths.

Results: Between 8.8 and 10.2\% of CHD morbidity was attributable to job strain, and between 9.4 and $11.2 \%$ of CHD mortality was attributable to this exposure for men. Between 15.2 and $19.8 \%$ of MD was attributable to job strain for men, and between 14.3 and 27.1\% for women. As a whole, between 450000 and 590000 cases of diseases and 910-1130 deaths were attributable to job strain for men. From 730000 to 1380000 cases of diseases and from 150 to 280 deaths were attributable to job strain for women. The total number of sick leave days amounted from 5 to 6.6 million days for men, and from 8.5 to 16 million days for women. The total costs of CHD and MD attributable to job strain exposure ranged from 1.8 to 3 billion euros for the year 2003 (0.12-0.19\% GDP). Medical costs accounted for $11 \%$ of the total costs, value of life costs accounted for $13-15 \%$ and sick leave costs for $74-77 \%$. The cost of CHD was estimated at 113-133 million euros and the cost of MD was between $1.7-2.8$ billion euros in 2003.

Conclusion: This study on the economic burden of diseases attributable to job strain in France provides relevant insights for policy-makers when defining public health priorities for prevention policies.

Keywords: Work stress, occupational stress, job stress, job strain, attributable fraction, cost, economic burden

\section{Background}

Work stress has become a major occupational risk factor in all industrialized countries [1] and an important economic issue. The high cost of work stress for employers, social security systems and society as a whole has been emphasized in numerous studies [2-5] but detailed evaluations

\footnotetext{
* Correspondence: sultan_taieb.helene@uqam.ca

'Département d'organisation et ressources humaines, Université du Québec à Montréal (UQAM), Montréal, Québec, Canada

${ }^{2}$ Centre de recherche interdisciplinaire sur la biologie, la santé, la société et I'environnement (CINBIOSE), Montréal, Québec, Canada

Full list of author information is available at the end of the article
}

of these costs have been very seldom in the literature. A few rough estimates were produced without explaining the method used for such estimates. For example, costs of work stress were estimated at $€ 20$ trillion in Europe per year [6], but details on the estimation method were not available. Moreover, the discrepancy between estimates can be very large [7]. This is partly due to the fact that work stress can be defined as a risk factor (related to working conditions and work organization) or as a health outcome related to mental disorders. For example, Hoel and al [8] estimated that the costs of work stress and bullying may

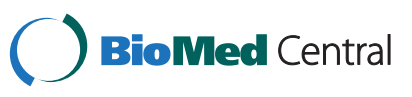


account for approximately $0.5-3.5 \%$ of GDP per year in 2000 in the UK (approx £4.9-34.1 billion), based on the hypothesis that these risk factors represented $30 \%$ of the overall cost of ill-health and accidents. The Health and Safety Executive in the UK estimated the cost of sickness absence due to stress, depression and anxiety perceived by the worker as being 'caused or made worse by work' (Labour Force Survey, UK) at $£ 530$ million in 2006 [9].

A way to evaluate the cost of work stress is to measure claims costs due to stress-related conditions at work. But this type of evaluation depends on national legislative frameworks which vary from one country to another. For example, in Australia, attempts have been made to reduce the costs of stress-related claims by modifying legislative thresholds on such claims [10]. In general, occupational exposures costs based on workers compensations only reflect a part of total costs, since occupational diseases or injuries have to be declared by workers [11-13] and covered by social welfare or insurance schemes to appear as claims [14].

Attributable fractions have been widely used in the literature to estimate the burden of diseases attributable to occupational exposures in terms of morbidity or mortality cases and disability-adjusted life years [15-20]. Attributable fraction can also be used to estimate the monetary cost of diseases attributable to occupational exposures but literature remains very sparse on this issue, except for some studies [21-23]. Studies are even less numerous when considering the costs of disease attributable to exposures to psychosocial risk factors at work [24-26]. However, precise and detailed economic evaluations of the costs associated to psychosocial work exposures are much needed to show the magnitude of the problem, and to provide guidance to policy makers when defining public health priorities and allocation of limited resources [27].

A large number of epidemiologic studies have shown that exposure to work stress is a risk factor for various health outcomes, especially cardiovascular diseases $[28,29]$ and mental disorders [30-32]. Less conclusive results have been found for musculoskeletal diseases [33,34]. The leading work stress model in the literature is Karasek's job strain model [35]. This model is based on two dimensions: psychological demands (i.e. job demands, time pressure, conflicting demands, etc.), and decision latitude (i.e. both control over work, named decision authority, and possibility of developing skills, named skill discretion). According to this model, the most detrimental situation is defined by the combination of high levels of psychological demands and low levels of decision latitude, and is called job strain. Data on the impact of job strain on workers' health are available in the literature and exposure to job strain has been measured in a national survey, representative of the working population, in France in 2003.
The aim of this article was to estimate the costs of cardiovascular diseases (CVD), and more precisely coronary heart diseases (CHD) and mental disorders (MD), i.e. two highly prevalent common mental disorders, depression and anxiety, attributable to job strain exposure in France in 2003 from a societal perspective, using a cost-of-illness approach [36,37]. A societal perspective is used to take account of all the costs associated with a disease, no matter who bears the costs, including health services and insurances, patients and the production system (lost production). This approach is considered as appropriate for decision making concerning public health policies [38-40].

\section{Methods}

\section{AF data and calculation}

As defined by Nurminen and Karjalainen [19], attributable fractions (AF) are an estimate of the fraction of cases that is "attributable to an exposure in a population and that would not have been observed if the exposure had been non-existent". AF calculations are based on relative risk $R R$ estimates (risks of disease or death due to exposure to the risk factor) and prevalence of exposure $P_{e}$ estimates (proportion of the population exposed to the risk factor) [41]:

$$
A F=P_{e}(R R-1) /\left(1+P_{e}(R R-1)\right)
$$

RR estimates were derived from a systematic literature review of prospective studies published in peer-reviewed journals between 1998 and 2008 (inclusive), i.e. a period centered around the year 2003. Inclusion criteria were a sufficient sample size (over 100 individuals) of a population in industrialized countries, with an explicit use of Karasek's model for exposure assessment and a precise measurement of health outcomes (clinically diagnosed or based on validated instruments). Only studies studying men and women separately and providing unadjusted (or age-adjusted) and multi-adjusted RRs/ORs were retained. This literature review excluded studies based on a job-exposure matrix known to underestimate RRs [42]. Fifteen prospective studies were selected, more details on the selection process of the literature review are available elsewhere [34].

In order to summarize the results of this literature review, we conducted meta-analyses based on this selection of studies. We retained 9 studies for CVD [43-51] among which 8 produced RRs for CHD and 1 study yielded RR estimates for CVD [46], i.e., for a broader range of cardiovascular outcomes. We included 6 studies for MD [52-57]. Depression and anxiety were evaluated using either validated self-administered questionnaires, such as the Beck Depression Inventory (BDI), Center for Epidemiologic Studies Depression Scale (CES-D), General Health Questionnaire (GHQ), and Psychiatric Symptom 
Index (PSI), or standardized diagnostic interviews such as CIDI (Composite International Diagnostic Interview). We calculated two sets of summary RR estimates separately based (1) on unadjusted or age-adjusted RRs and (2) on multi-adjusted RRs. We produced summary estimates for men and women separately. We used a random effects method with inverse variance weighting, which is considered as more conservative than the fixed effects method $[28,30]$. Two indicators of heterogeneity between studies were used: Cochran's Q statistic with a $p$ value $<0.05$ for a significant heterogeneity and the $\mathrm{I}^{2}$ statistic [58]. We used Stata software for meta-analysis calculations.

The data used for the estimate of prevalence of exposure $\mathrm{P}_{\mathrm{e}}$ to job strain came from the national SUMER survey which was conducted in France in 2003. This survey is a periodical cross-sectional survey conducted by the French Ministry of Labour (DARES) and including a selfadministered questionnaire, including Karasek's Job Content Questionnaire (JCQ). In total, 24,486 employees, 12,241 men and 10,245 women, selected on a random basis responded to the JCQ (response rate: 96.5\%). The data of the SUMER survey were weighted to provide estimates that were representative of the French working population. As a result, the 2003 SUMER survey provides high quality data for exposure to job strain among the French national working population according to gender [42,59-62]. The estimates for the prevalence of job strain exposure obtained from the SUMER survey were $19.6 \%$ for men, $28.2 \%$ for women, and $23.2 \%$ for the total population.

We produced a range of attributable fraction (AF) values. The AF low range value for each disease was calculated using multi-adjusted RR summary estimates in formula (1) and the AF high range value was based on age-adjusted RR summary estimates. In this calculation, we assumed that ORs were satisfactory estimates for RRs, which allowed to use ORs for AFs calculation in formula (1).

We computed confidence intervals at $95 \%$, based on 100000 simulated distributions of $P_{e}$ and $R R$, with the hypothesis that $R R$ and $P_{e}$ follow independent normal distributions. Confidence intervals were calculated with the mean and standard deviation from the simulated values of AFs. We used SAS software for simulation calculations.

\section{Data on prevalence of diseases}

We considered all national surveys available in France for the number of cases (morbidity and mortality) of CVD and MD. Inclusion criteria were a definition of disease corresponding to health outcomes used in our summary RR estimates, the availability of data for men and women separately, the availability of data for workingage population, and the survey had to be conducted in 2003 or as close as possible to 2003.

\section{CHD morbidity data}

Since most of the selected studies for CVD produced RRs for CHD (8 studies out of 9), we retained prevalence and costs data on CHD rather than CVD to ensure consistency between data used in our estimation. We used the prevalence of CHD (CIM 10, codes I20-I25) from the database of the Health and Social Benefits Survey (Enquête Santé et Protection Sociale) conducted in France in 2004 by IRDES (Institut de Recherche et Documentation en Économie de la Santé). Weighted prevalence data were computed and provided by IRDES for men $(1.38 \%)$ and women $(0.37 \%)$ from 18 to 64 years. We assumed a stable prevalence of CHD between 2003 and 2004 in France.

\section{CHD mortality data}

We used mortality data in 2003 from the database of the Epidemiological Center for the Medical Causes of Death (Centre d'Épidémiologie sur les Causes Médicales de Décès, CEPIDC) [63]. It provides the number of deaths from CHD (CIM 10, codes I20-I25) for men and women from 20 to 64 years.

\section{MD morbidity data}

We computed the prevalence of MD (depression and anxiety) from a French national survey, the Ten-yearly Health survey 2002-2003 (Enquête Décennale Santé). Data were weighted by age and gender. MD were defined by a score obtained to CES-D equal or higher than 16. The prevalence of MD for the population from 18 to 64 years was $15.5 \%$ (95\% confidence interval: $14.6 \%$ $16.4 \%$ ) for men and $27.4 \%$ (95\% confidence interval: 26.4\%-28.4\%) for women in France.

\section{MD mortality data}

We used data about the prevalence of suicide in 2003 provided by the Epidemiological Center for the Medical Causes of Death (Centre d'Épidémiologie sur les Causes Médicales de Décès, CEPIDC) for men and women from 20 to 64 years [63]. Based on an analysis of the literature [64-66], we assumed that from 54 to $64 \%$ of suicides were due to depression. A sensitivity analysis was conducted to take account of these two percentages.

Another sensitivity analysis was conducted using a more restrictive definition of mental disorders based on depression alone. For this analysis, we used depression morbidity data produced by ESEMED study (European Study of the Epidemiology of Mental disorders) which was based on a standardized diagnostic interview (WMHCIDI: World Mental Health- Composite International Diagnostic Interview). According to this survey, the prevalence of depression was $4.7 \%$ (95\% confidence interval: $3.6 \%-5.8 \%$ ) for men and $8.5 \%$ (95\% confidence interval: 7.1\%-9.9\%) for women in France [67]. We computed AF 
estimates for depression using job strain RR estimates provided by Shields's [57] study. It was the only study in our literature review based on a measure of depression using a standardized diagnostic interview (CIDI) and producing both crude and multi-adjusted RR estimates.

\section{Cost data and calculation}

Costs $C$ were estimated from a societal perspective according to a prevalence approach and based on French data. They included medical costs $M$ of CHD and MD and indirect costs: production losses due to sick leaves $S$ and to premature deaths $D$ attributable to job strain exposure, according to the following formula:

$$
C=\sum_{i}^{C V D, M D}\left(M_{i}+S_{i}+D_{i}\right) A F_{i}
$$

where $A F_{i}$ is the attributable fraction corresponding to disease $i$ (CHD or MD). Data on production losses due to early retirement and to presenteeism were not available. For the data on medical and indirect costs of diseases we conducted a systematic review of French and international databases, reports (EUROHEED-CODECS, DREES, IRDES, CNAMTS, Base BDSP, OECD, WHO) and articles published in peer reviewed journals through Medline interrogations.

Indirect costs were calculated on the basis of the human capital hypothesis [68], by multiplying the number of lost days because of illness with the Gross Domestic Product per capita and per working day $\left(G D P_{c d}\right)$ for the year 2003 in France. The value of production losses due to premature death is estimated to take account of the lost production due to the number of years lost between the age of death and the average retirement age, as shown in formula (3):

$$
V L Y=G D P_{c d} \sum_{a}\left(N_{a} \sum_{y=1}^{R-a} \frac{(1+g)^{y}}{(1+r)^{y}}\right)
$$

Where $V L Y$ is the value of lost years of production due to disease (CHD or MD), GDP ${ }_{c d}$ is the French Gross Domestic Product per capita and per working day, $N_{a}$ is the number of deaths due to the disease at the age $a$ in the French population, $R-a$ is the number of years lost between the age of death $a$ and the average retirement age $R, g$ is the annual growth rate of GDP and $r$ the discount rate. A discount rate of $5 \%$ and a growth rate of $2 \%$ were posited, as generally assumed.

A sensitivity analysis was conducted to take account of the two range values for the number of suicides due to depression in the literature $(54 \%$ or $64 \%$ ) and the two values of attributable fractions which we computed (from multi or age-adjusted RRs).

\section{CHD medical costs}

According to Paris and al [69], CHD represented 16\% of national consumption of medical care and goods for diseases of the circulatory system in France in 1998. And according to Fenina and al [70], diseases of the circulatory system represented $12.6 \%$ of the total consumption of medical care and goods in France in 2002. We assumed that average medical expenses for each case of CHD were the same between genders and age groups and a stable proportion of CHD medical expenses in total consumption of medical care and goods from 1998 to 2003 in France.

\section{CHD indirect costs}

Statistics from the public medical care system provided the number of sick leave days as prescribed by cardiologists in France in 2003 [71]. We made the assumption that the distribution of sick leave days between men and women was similar to the distribution of CHD cases between genders.

\section{MD medical costs}

According to Paris and al [69], depression represented $1.05 \%$ of the total consumption of medical care and goods in France in 1998. We assumed that medical expenses for each case of MD were the same between genders and age groups and a stable proportion of MD medical expenses in total consumption of medical care and goods from 1998 to 2003.

\section{$M D$ indirect costs}

A study by Morvan et al. [72], on the basis of a national survey conducted in France in 2005 (Baromètre Santé 2005), produced the proportion of mild, average and severe episodes of depression in the population suffering from depression and the corresponding number of sick leave days per year. According to this survey, $17.8 \%$ of persons suffering from mild depressive episodes take an average of 10.4 sick leave days per year. $26.2 \%$ of persons suffering from average depressive episodes take an average of 49.2 sick leave days per year. And $48.9 \%$ of persons suffering from major depressive episodes take an average of 108.1 sick leave days per year. We assumed that the distribution of sick leave days between men and women was similar to the distribution of depression cases between genders. We also assumed that the number of sick leave days was stable between 2003 and 2005 . Health reasons for sick leaves are not available in health insurance databases in France because the medical cause of absence is covered by confidentiality.

\section{Results}

Meta-analysis results are shown in Figure 1. Summary RR estimates for CHD morbidity were significant for 


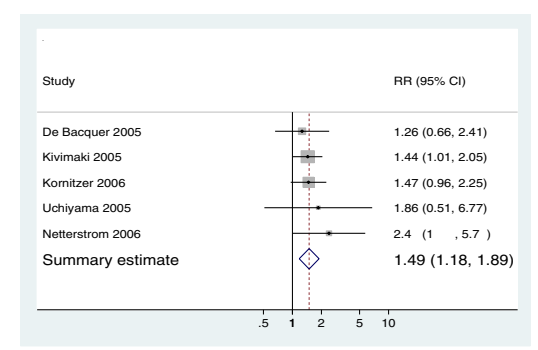

Job strain and CVD morbidity among men, multi-adjusted relative risk (Heterogeneity: $\mathrm{Q}=1.56$, d.f. $=4, \mathrm{p}=0.82 ; \mathrm{I}^{2}=0.0 \%$ )

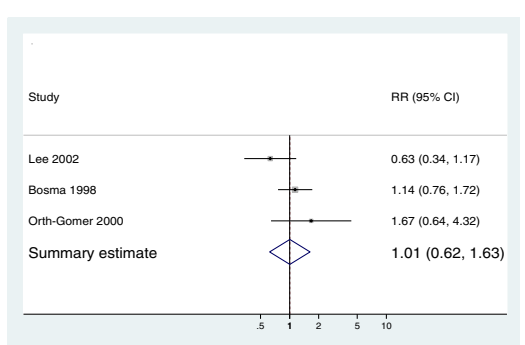

Job strain and CVD morbidity among women, multi-adjusted relative risk (Heterogeneity: $\mathrm{Q}=3.34$, d.f. $=2, \mathrm{p}=0.16 ; \mathrm{I}^{2}=45.1 \%$ )

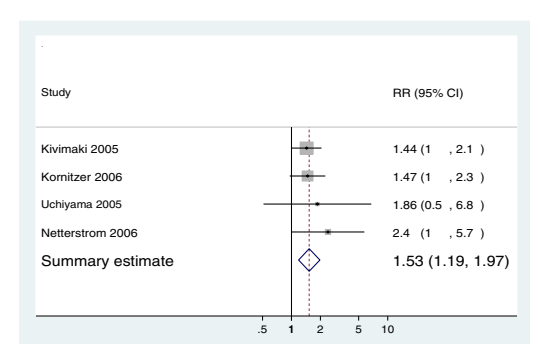

Job strain and CVD mortality among men, multi-adjusted relative risk (Heterogeneity: $\mathrm{Q}=1.26$, d.f. $=3$, $\mathrm{p}=0.74 ; \mathrm{I}^{2}=0.0 \%$ )

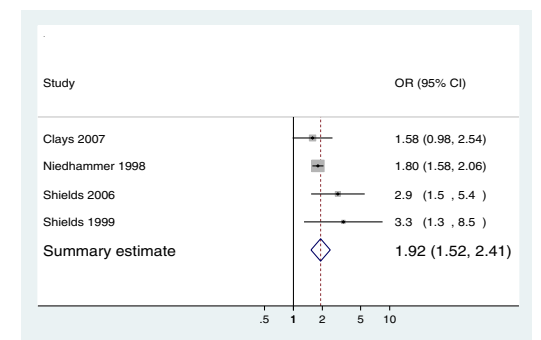

Job strain and mental disorders among men, multi-adjusted odds-ratio (Heterogeneity: Q=3.92, d.f. $=3, \mathrm{p}=0.27 ; \mathrm{I}^{2}=23.5 \%$ )

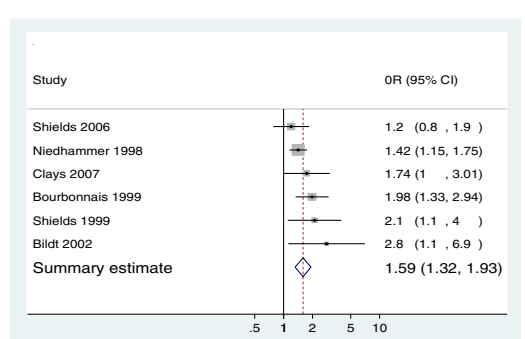

Job strain and mental disorders among women, multi-adjusted oddsratio (Heterogeneity: $\mathrm{Q}=6.09$, d.f. $=5$, $\mathrm{p}=0.30 ; \mathrm{I}^{2}=17.9 \%$ )

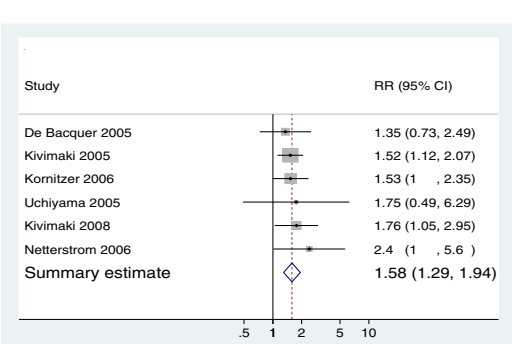

Job strain and CVD morbidity among men, age-adjusted relative risk (Heterogeneity: $\mathrm{Q}=1.43$, d.f. $=5$, $\mathrm{p}=0.92 ; \mathrm{I}^{2}=0.0 \%$ )

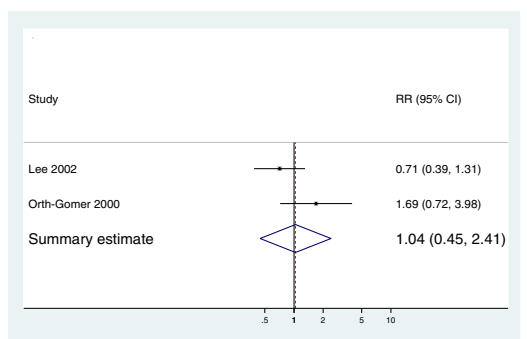

Job strain and CVD morbidity among women, age-adjusted relative risk (Heterogeneity: $\mathrm{Q}=2.63$, d.f. $=1, \mathrm{p}=0.105 ; \mathrm{I}^{2}=62.0 \%$ )

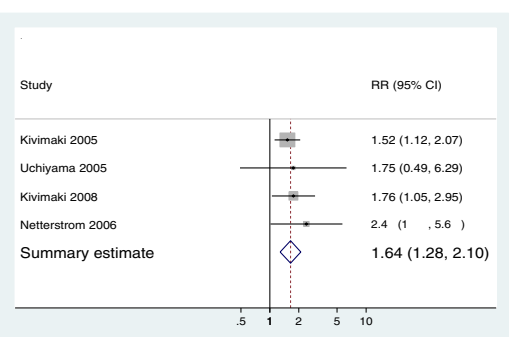

Job strain and CVD mortality among men, age-adjusted relative risk (Heterogeneity: $\mathrm{Q}=1.07$, d.f. $=3$, $\mathrm{p}=0.79 ; \mathrm{I}^{2}=0.0 \%$ )

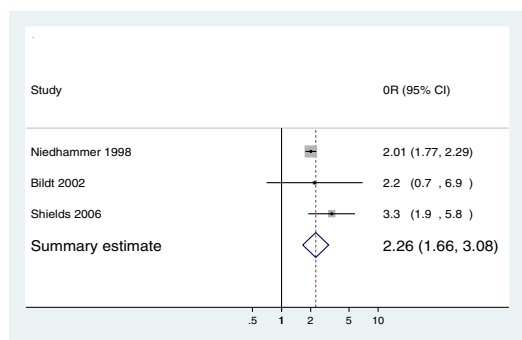

Job strain and mental disorders among men, age-adjusted or unadjusted odds-ratio (Heterogeneity: $\mathrm{Q}=2.89$, d.f. $=2, \mathrm{p}=0.24 ; \mathrm{I}^{2}=30.8 \%$ )

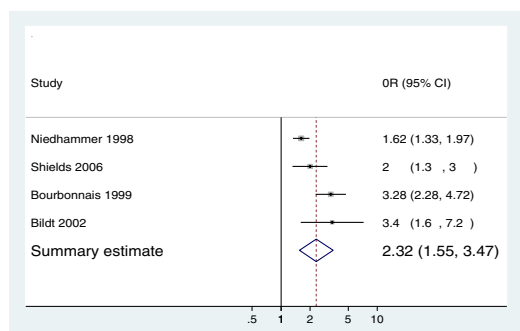

Job strain and mental disorders among women, age-adjusted or unadjusted odds-ratio (Heterogeneity : $Q=13.4$, d.f. $=3, \quad p=0.004$; $\mathrm{I}^{2}=77.6 \%$ ) 
men, 1.49 and 1.58, and not significant for women, 1.01 and 1.04. Significant summary RRs for CHD mortality were 1.53 and 1.64 for men. There was no multi-adjusted RR for CHD mortality among women and only one nonsignificant age-adjusted RR estimate. Thus available data did not allow the calculation of summary RR estimates for CHD mortality among women. Summary OR estimates for MD were significant for both genders, 1.92 and 2.26 for men, 1.59 and 2.32 for women. Summary RR and OR estimates and 95\% confidence intervals are shown in Table 1.

For men, 8.8-10.2\% of CHD morbidity was attributable to job strain. Attributable fractions (AF) for CHD mortality were $9.4-11.2 \%$ for men. AFs for CHD morbidity and mortality for women yielded non significant values (Table 2). Therefore, we could not infer the burden of CHD attributable to job strain exposure for women, for lack of significant RR data. Between 15.2 and 19.8\% of MD were attributable to job strain for men, and between 14.3 and $27.1 \%$ for women, these two AFs being significant. AF estimates and 95\% confidence intervals are shown in Table 2.

Between 22071 and 25743 cases of CHD were attributable to job strain exposure, and between 442 and 524 deaths among men. For MD, between 430470 and 559 215 cases for men and 727 266-1 378718 cases for women were attributable to job strain exposure. Between 619 and 894 deaths (suicides associated with depression) for men and women were attributable to this exposure. The number of sick leave days lost because of CHD attributable to job strain went from 55015 to 64167 days. For MD, the number of lost working days amounted from 5016529 to 6516864 days for men and from 8 475264 to 16067034 days for women (Table 3).

The total costs of CHD and MD attributable to job strain exposure ranged from approximately 1.8 to 3 billion euros per year in France. This cost included medical costs, the value of sick leave days lost because of disease, and the value of life years lost because of premature death. The cost of CHD was estimated at 113-133 million euros. The cost of MD was around 1.7 and 2.8 billion euros. Results are shown in Table 4.
We computed a sensitivity analysis based on a less conservative hypothesis for the percentage of suicides associated with depression, according to data available in the literature [64-66]. Assuming that $64 \%$ of suicides were associated with depression instead of $54 \%$, the number of deaths related to MD attributable to job strain was between 556 and 723 for men, and between 178 and 337 for women. As a result, the total number of deaths increased by $18.5 \%$ and the total costs increased by around $2 \%$. Therefore, this alternative hypothesis had a limited impact on the total costs attributable to job strain exposure.

We also conducted a more conservative analysis based on a restrictive definition of mental disorders, including depression only. RR estimates for depression were derived from Shields's study [57] and were from 2.9 to 3.3 for men and from 1.2 to 2 for women, with a nonsignificant multi-adjusted RR estimate for women. Thus, available data did not allow the calculation of AF based on multi-adjusted RR estimate for women. For men, $27.2-31.1 \%$ of depression was attributable to job strain and 22\% for women. Between 232308 and 266007 cases of depression for men and 346172 cases of depression for women were attributable to job strain exposure. The number of lost working days because of depression attributable to job strain amounted from 2707220 to 7 134 095 days for men and women. The cost of depression attributable to job strain was between 780 million and 1.6 billion euros.

\section{Discussion}

Between 8.8 and $10.2 \%$ of CHD morbidity was attributable to job strain, and between 9.4 and $11.2 \%$ of $\mathrm{CHD}$ mortality was attributable to this exposure for men. Between 15.2 and $19.8 \%$ of MD (depression and anxiety) was attributable to job strain for men, between 14.3 and $27.1 \%$ for women. As a whole, between 450000 and 590 000 cases of diseases and $910-1130$ deaths were attributable to job strain for men. From 730000 to 1380000 cases of diseases and from 150 to 280 deaths were attributable to job strain for women. The number of deaths attributable to job strain is approximately twice the

Table 1 Summary relative risks (RR) and odds-ratios (OR) on the association between job strain and coronary heart diseases (CHD) and mental disorders (MD)

\begin{tabular}{|c|c|c|c|c|c|c|c|c|c|c|}
\hline \multirow[b]{3}{*}{ Men } & \multirow[b]{3}{*}{$M-A$} & \multicolumn{6}{|c|}{ CHD } & \multicolumn{3}{|c|}{ MD } \\
\hline & & \multirow{2}{*}{$\begin{array}{c}\text { Morbidity RR } \\
1.49\end{array}$} & \multicolumn{2}{|c|}{$95 \% \mathrm{Cl}$} & \multirow{2}{*}{$\begin{array}{c}\text { Mortality RR } \\
1.53\end{array}$} & \multicolumn{2}{|c|}{$95 \% \mathrm{Cl}$} & \multirow{2}{*}{$\begin{array}{c}\text { Morbidity OR } \\
1.92\end{array}$} & \multicolumn{2}{|c|}{$95 \% \mathrm{Cl}$} \\
\hline & & & 1.18 & 1.89 & & 1.19 & 1.98 & & 1.52 & 2.41 \\
\hline & $A-A$ & 1.58 & 1.29 & 1.94 & 1.64 & 1.28 & 2.10 & 2.26 & 1.66 & 3.08 \\
\hline \multirow[t]{2}{*}{ Women } & $M-A$ & 1.01 & 0.62 & 1.63 & / & & & 1.59 & 1.32 & 1.93 \\
\hline & $A-A$ & 1.04 & 0.45 & 2.41 & $1.09^{*}$ & 0.4 & 2.92 & 2.32 & 1.55 & 3.47 \\
\hline
\end{tabular}

M-A: multi-adjusted, A-A: age-adjusted or unadjusted.

* Estimate from one study only (Lee et al., [48]), not a summary RR.

$95 \% \mathrm{Cl}$ : confidence interval at $95 \%$. 
Table 2 Fractions of coronary heart diseases (CHD) and mental disorders (MD) attributable to job strain in France (\%)

\begin{tabular}{|c|c|c|c|c|c|c|c|c|c|c|c|c|c|}
\hline \multirow{3}{*}{ Men } & \multirow[b]{3}{*}{$M-A$} & \multicolumn{6}{|c|}{ CHD } & \multicolumn{6}{|c|}{ MD } \\
\hline & & \multirow{2}{*}{$\begin{array}{c}\text { Morbidity } \\
8.8\end{array}$} & \multicolumn{2}{|c|}{$95 \% \mathrm{Cl}$} & \multirow{2}{*}{$\begin{array}{c}\text { Mortality } \\
9.4\end{array}$} & \multicolumn{2}{|c|}{$95 \% \mathrm{Cl}$} & \multirow{2}{*}{$\begin{array}{c}\text { Morbidity } \\
15.2\end{array}$} & \multicolumn{2}{|c|}{$95 \% \mathrm{Cl}$} & \multirow{2}{*}{$\begin{array}{c}\text { Mortality } \\
15.2\end{array}$} & \multicolumn{2}{|c|}{$95 \% \mathrm{Cl}$} \\
\hline & & & 3.2 & 14.7 & & 3.3 & 15.9 & & 9.0 & 21.5 & & 9.0 & 21.5 \\
\hline & $A-A$ & 10.2 & 5.2 & 15.4 & 11.2 & 4.9 & 17.5 & 19.8 & 11.1 & 28.7 & 19.8 & 11.1 & 28.7 \\
\hline \multirow[t]{2}{*}{ Women } & $M-A$ & 0.2 & -13.1 & 14.1 & I & & & 14.3 & 8.1 & 20.7 & 14.3 & 8.1 & 20.7 \\
\hline & $A-A$ & 1.1 & -21.6 & 25.9 & 2.5 & -24.7 & 31.9 & 27.1 & 13.2 & 41.0 & 27.1 & 13.2 & 41.0 \\
\hline
\end{tabular}

M-A: attributable fraction based on multi-adjusted relative risk, A-A: attributable fraction based on age-adjusted or unadjusted relative risk. $95 \% \mathrm{Cl}$ : confidence interval at $95 \%$.

number of deaths due work fatalities declared in France in 2003. The total number of sick leave days for the year 2003 amounted from 5 to 6.6 million days for men, and from 8.5 to 16 million days for women. The total costs of $\mathrm{CHD}$ and MD attributable to job strain exposure ranged from approximately 1.8 to 3 billion euros for the year 2003 in France (0.12-0.19\% GDP). Medical costs accounted for $11 \%$ of the total costs, value of life costs accounted for $13-15 \%$ and sick leave costs for $74-77 \%$. The cost of CHD was estimated at 113-133 million euros and the cost of MD was between 1.7 and 2.8 billion euros. Thus MD accounted for approximately 94$96 \%$ of the total costs attributable to job strain exposure. This is due to a higher prevalence of the disease among the population of working age, higher levels of attributable fractions, and also a high amount of sick leave days due to MD. The sensitivity analysis conducted on a more restrictive definition of mental disorders including depression only, produced much lower values in terms of number of cases and costs. This calculation can be considered as very conservative. Indeed, the definition of mental disorders was restricted to clinical depression, and thus excluded anxiety but also symptomatic cases of depression and anxiety. Furthermore, the RR estimates were based on only one available prospective study that produced RR estimates using a standardized diagnostic interview (CIDI) [57]. This study yielded non-significant multi-adjusted RR estimates for women, which did not allow to calculate a low range value of AF estimates.

Some limitations of the study must be pointed out. This estimate of the cost of diseases attributable to job strain exposure may be more under-estimated than over-estimated. We did not produce AF estimates of CHD morbidity and mortality for women since available data were very scarce and the rare included studies yielded non-significant RRs. Therefore the estimation of the cost of CHD attributable to job strain was provided for men only. Another way of interpreting the results may be that our estimates of costs may be null for women, something that may be a bit premature to conclude given the scarcity of the literature. Indeed, recent studies show an increase in CVD prevalence among women in the French population [73,74], which underlines the need for more investigations on the etiological role of job strain on CVD among women. The estimates did not take account of potential delayed effects of job strain exposure on cardiovascular or mental health. We included only CHD and MD in our study. The number of studies selected in our literature review was very small for musculoskeletal disorders (MSD) and concerned different locations (back, low back, neck, shoulder, upper extremity, elbow, hand, and wrist) [34]. Therefore we could not compute a summary OR and AF estimates for a specific MSD location which could be used for cost of illness estimates.

Table 3 Burden of coronary heart diseases (CHD) and mental disorders (MD) imputable to job strain exposure in France in 2003

\begin{tabular}{|c|c|c|c|c|c|c|}
\hline & \multicolumn{2}{|c|}{ Men } & \multicolumn{2}{|c|}{ Women } & \multicolumn{2}{|c|}{ Total } \\
\hline & Multi-adjusted & Age-adjusted & Multi-adjusted & Age-adjusted & Multi-adjusted & Age-adjusted \\
\hline CHD morbidity & 22071 & 25743 & - & - & 22071 & 25743 \\
\hline CHD mortality & 442 & 524 & - & - & 442 & 524 \\
\hline MD morbidity & 430470 & 559215 & 727266 & 1378718 & 1157736 & 1937933 \\
\hline MD mortality & 469 & 610 & 150 & 284 & 619 & 894 \\
\hline Number of sick leave days for $\mathrm{CHD}$ & 55015 & 64167 & - & - & 55015 & 64167 \\
\hline Number of sick leave days for MD & 5016529 & 6516864 & 8475264 & 16067034 & 13491794 & 22583898 \\
\hline Total number of cases & 452542 & 584957 & 727266 & 1378718 & 1179807 & 1963676 \\
\hline Total number of deaths & 912 & 1134 & 150 & 284 & 1062 & 1418 \\
\hline Total number of sick leave days & 5071545 & 6581031 & 8475264 & 16067034 & 13546809 & 22648065 \\
\hline
\end{tabular}


Table 4 Costs of diseases imputable to job strain en France in 2003 (euros)

\begin{tabular}{|c|c|c|c|c|c|c|}
\hline & \multicolumn{2}{|c|}{ Men } & \multicolumn{2}{|c|}{ Women } & \multicolumn{2}{|c|}{ Total } \\
\hline & Multi-adjusted & Age-adjusted & Multi-adjusted & Age-adjusted & Multi-adjusted & Age-adjusted \\
\hline \multicolumn{7}{|l|}{$\mathrm{CHD}$} \\
\hline Medical costs & 41107656 & 47945576 & & & 41107656 & 47945576 \\
\hline Sick leave costs & 5543673 & 6465817 & & & 5543673 & 6465817 \\
\hline Value of life costs & 66565007 & 78813896 & & & 66565007 & 78813896 \\
\hline Total CHD & 113216336 & 133225290 & - & - & 113216336 & 133225290 \\
\hline \multicolumn{7}{|l|}{$\mathrm{MD}$} \\
\hline Medical costs & 60368981 & 78424030 & 101991441 & 193350898 & 162360422 & 271774928 \\
\hline Sick leave costs & 505494140 & 656676437 & 854015999 & 1619006057 & 1359510139 & 2275682494 \\
\hline Value of life costs & 156839921 & 203747328 & 47243181 & 89561550 & 204083102 & 293308877 \\
\hline Total MD & 722703042 & 938847795 & 1003250621 & 1901918505 & 1725953663 & 2840766300 \\
\hline Total & 835919378 & 1072073084 & 1003250621 & 1901918505 & 1839170000 & 2973991589 \\
\hline
\end{tabular}

CHD: coronary heart diseases, MD: mental disorders.

Our study grasped only a part of the total amount of costs attributable to work stress since job strain is only one aspect of stress among other concepts, such as Effort-Reward Imbalance developed by Siegrist [75]. Cost data had also some limitations. Costs did not include production losses due to presenteeism and to early retirement for lack of data. Other cost categories could not be included in our estimates, such as the costs of informal care (provided by families and friends), intangible costs (cost of suffering, pain and discomfort) and the cost of job turnover for lack of data. We also limited the value of lost years of life to the value of lost production. We did not take account of the total losses of social welfare due to deaths through an estimation of willingness to pay or value of a statistical life for instance, for lack of available data. For all these reasons, our estimates can be considered as conservative. In addition, we made a number of assumptions in our calculations and these assumptions may not be verified easily. For example, we assumed that the RR of mental disorders associated with job strain was the same for morbidity and mortality, something that may be consistent for cardiovascular diseases but was not checked for mental disorders, the literature being rare on this topic [76]. Another example, the proportion of suicides due to depression was estimated to be $54 \%-64 \%$ of the total number of suicides in the general population but it was not possible to check whether these figures may be used for the working population.

This study has also several strengths. Our metaanalyses for RR estimates showed a satisfactory homogeneity between studies, except for age-adjusted ORs of MD for women which yielded a significant level of heterogeneity. Overall, the risk of heterogeneity between studies was mitigated by the fact that we included only high quality studies in our systematic review of the literature, with similar exposure and with statistical analyses allowing the estimation of RRs. The data we used are highly consistent: RR, prevalence of exposure, prevalence of disease and cost data are based on the same definition of disease and exposure. To ensure such consistency, we conducted a systematic review of the literature for disease prevalence and costs data in France and we produced data for each gender separately. The only exception may be the use of mental disorders medical costs based on the medical cost of depression only that may underestimate the costs of mental disorders attributable to job strain. We performed a sensibility analysis including depression only to provide a very conservative estimate of mental disorders costs attributable to job strain. The medical costs used in our study included out-of pocket payments by patients along with medical expenses paid by insurances, which is well appropriate for estimations from a societal perspective. We produced two range values of AF estimates with confidence intervals, based on a meta-analysis of RRs. Our calculation method had several strengths: we took account of multi-adjusted and age-adjusted estimates in our calculations, which produced the AF range values. And we combined this approach to meta-analyses to get more precise estimates of AFs based on available data in the literature. This method allowed us to encompass various high-quality RR estimates in our summary RRs, and at the same time to take account of a certain level of uncertainty regarding RRs, since age-adjusted and multiadjusted estimates yielded different values.

Our summary RRs for CVD are consistent with those from the meta-analysis by Kivimaki et al. [28] providing a summary age and gender-adjusted RR of 1.45 (95\% CI: 1.15-1.84) and a multi-adjusted RR of 1.16 (95\% CI: 0.94-1.43). Our RR estimates regarding men are higher, but this difference could be explained by the fact that Kivimaki et al's estimates included both men and women. Our results for MD are also consistent with 
those summarized in the meta-analysis by Stansfeld and Candy [30] (summary OR: 1.82, 95\% CI: 1.06-3.10). Our estimates of attributable fractions for CVD mortality are more conservative than those reported by Nurminen \& Karjalainen [19], who found estimates of $16 \%$ for men for the fractions of cardiovascular deaths attributable to job strain in Finland. Our AF estimates for MD are in line with those of LaMontagne et al. [77] who reported fractions of $13.2 \%$ for men and $17.2 \%$ for women attributable to job strain in Australia. Their fractions resulted from the summary OR estimates from Stansfeld and Candy's meta-analysis [30]. Our results are higher than the costs of diseases attributable to job strain exposure in a previous study by Béjean et Sultan-Taïeb [25]. For the year 2000 in France, total costs amounted for 1.2-1.6 billion euros but included also musculoskeletal disorders. Differences can be explained by the fact that the fractions of MD for women were underestimated (4.8\%) since they were based on a limited selection of OR estimates in the literature. The cost of depression attributable to job strain in Australia was estimated by LaMontagne et al. [26] at 730 million dollars AUD (approx.. 510 million euros) in 2007, given that 1.54 million persons suffer from depression in the Australian workforce. It is however difficult to compare these results with ours since categories of costs included in the estimations are different: job turnover and presenteeism costs are included in LaMontagne et al.'s study, while indirect costs related to premature death (suicide) are excluded.

Our results provide an evaluation at one point of time, allowing projections of the cost of job strain according to the evolution of working environments and the trend of prevalence of exposure to job strain. It also allows comparisons with other countries. Our summary estimates of RRs for CHD and MD could be used for AF calculations in other countries where the prevalence of exposure to job strain has been measured in the working population.

\section{Conclusions}

This study on the economic burden of diseases attributable to job strain in France provides relevant insights for policy-makers when defining public health priorities for prevention policies. Diseases attributable to job strain and related costs are avoidable since effective intervention strategies to prevent job stress have been identified in several literature reviews [78-80]. Our results highlight potential economic implications of the development of such prevention policies.

\section{Competing interests}

The authors declare that they have no competing interests.

\section{Authors' contributions}

HST conceived and conducted the study, directed the literature review of economic data, participated in the literature review of epidemiologic data, performed the statistical analysis of cost estimates, and wrote the manuscript. JFC performed the statistical analysis of summary RRs/ORs and prevalence of diseases, and contributed to the review of successive drafts of the manuscript. MM participated in the literature review of economic data. IN directed the literature review of epidemiologic data, and participated in study conception and manuscript writing. All authors read and approved the final manuscript.

\section{Acknowledgement}

We thank IRDES (Institut de Recherche et Documentation en Économie de la Santé) and Catherine Sermet for providing weighted prevalence data of coronary heart diseases (CHD) for men and women based on the database of the Health and Social Benefits Survey (Enquête Santé et Protection Sociale) conducted in France in 2004.

\section{Funding}

Agence Nationale de la Recherche, France (ANR).

\section{Author details}

${ }^{1}$ Département d'organisation et ressources humaines, Université du Québec à Montréal (UQAM), Montréal, Québec, Canada. ${ }^{2}$ Centre de recherche interdisciplinaire sur la biologie, la santé, la société et l'environnement (CINBIOSE), Montréal, Québec, Canada. ${ }^{3}$ Laboratoire d'Économie Gestion (UMR CNRS 5118), Université de Bourgogne, Dijon, France. " INSERM, U1018, CESP Centre for research in epidemiology and population health, Epidemiology of occupational and social determinants of health team, Villejuif, France. ${ }^{5}$ Univ Paris-Sud, UMRS 1018, Villejuif, France. ${ }^{6}$ Université de Versailles St-Quentin, UMRS 1018, Villejuif, France.

Received: 20 December 2012 Accepted: 31 July 2013

Published: 13 August 2013

\section{References}

1. World Health Organization: Closing the gap in a generation : health equity through action on the social determinants of health. Final report of the Commission on Social Determinants of Health. Geneva: World Health Organization; 2008:248.

2. Cahalin LP: Job strain and older workers: Can a reduction in job strain help to eliminate the social security drain? Work 2009, 33(1):3-12.

3. Kalia M: Assessing the economic impact of stress-the modern day hidden epidemic. Metabolism 2002, 51(6 Suppl 1):49-53.

4. Shain M: The role of the workplace in the production and containment of health costs: the case of stress-related disorders. Int J Health Care Qual Assur Inc Leadersh Health Serv 1999, 12(2-3):i-vii.

5. Liukkonen P, Cartwright S, Cooper C: Costs and benefits of stress prevention in organisations. In Preventing stress, improving productivity: European case studies in the workplace. Edited by Kompier M, Cooper CL. London: Routledge; 1999:33-50.

6. Koukoulaki T: La prévention du stress au travail en Europe : aperçu des activités syndicales - obstacles et stratégies futures. BTS Newsletter. 2002, 19-20:4-12

7. Brun JP: Mental capital and wellbeing: Making the most of ourselves in the 21st century. Quebec: Government Office for Science; 2008.

8. Hoel H, Sparks K, Cooper CL: The cost of violence/stress at work and the benefits of a violence/stress-free working environment. Report commissioned by the International Labour Organization (ILO). Geneva: University of Manchester Institute of Science and Technology; 2001.

9. HSE (Health and Safety Executive): Workplace stress costs Great Britain in excess of $£ 530$ million. Press release: Health and Safety Executive. C021:07(7/ 11/2007) [cited 2012] Available from: http://www.hse.gov.uk/press/2007/ c07019.htm.

10. Guthrie R, Ciccarelli M, Babic A: Work-related stress in Australia: The effects of legislative interventions and the cost of treatment. Int J Law Psychiatry 2010, 33(2):101-115. Mar-Apr.

11. Biddle J, Roberts K, Rosenman KD, Welch EM: What percentage of workers with work-related illnesses receive workers' compensation benefits? J Occup Environ Med 1998, 40(4):325-331.

12. Leigh JP, Robbins JA: Occupational disease and workers' compensation: coverage, costs, and consequences. Milbank Q 2004, 82(4):689-721.

13. Bonauto DK, Smith CK, Adams DA, Fan ZJ, Silverstein BA, Foley MP: Language preference and non-traumatic low back disorders in 
Washington State workers' compensation. Am J Ind Med 2010, 53(2):204-215

14. Fayad R, Nuwayhid I, Tamim H, Kassak K, Khogali M: Cost of work-related injuries in insured workplaces in Lebanon. Bull World Health Organ 2003, 81(7):509-516

15. Fingerhut $M$, Driscoll T, Nelson DI, Concha-Barrientos M, Punnett L, Pruss-Ustin A, et al: Contribution of occupational risk factors to the global burden of disease - a summary of findings. Scand J Work Environ Health 2005, 1(suppl):59-61.

16. Nelson DI, Concha-Barrientos M, Driscoll T, Steenland K, Fingerhut M, Punnett $L$, et al: The global burden of selected occupational diseases and injury risks: Methodology and summary. Am J Ind Med 2005, 48(6):400-418.

17. Driscoll T, Takala J, Steenland K, Corvalan C, Fingerhut M: Review of estimates of the global burden of injury and illness due to occupational exposures. Am J Ind Med 2005, 48(6):491-502

18. Steenland K, Burnett C, Lalich N, Ward E, Hurrell J: Dying for work: The magnitude of US mortality from selected causes of death associated with occupation. Am J Ind Med 2003, 43(5):461-482.

19. Nurminen $M$, Karjalainen A: Epidemiologic estimate of the proportion of fatalities related to occupational factors in Finland. Scand J Work Environ Health 2001, 27(3):161-213.

20. t'Mannetje A, Pearce N: Quantitative estimates of work-related death, disease and injury in New Zealand. Scand J Work Environ Health 2005, 31 (4):266-276. Aug

21. Leigh JP, Markowitz SB, Fahs M, Shin C, Landrigan PJ: Occupational injury and illness in the United States. Estimates of costs, morbidity, and mortality. Arch Intern Med 1997, 157(14):1557-1568.

22. Leigh JP, Cone JE, Harrison R: Costs of occupational injuries and illnesses in California. Prev Med 2001, 32(5):393-406.

23. Leigh JP: Economic burden of occupational injury and illness in the United States. Milbank Q 2011, 89(4):728-772.

24. Levi L, Lunde Jensen P: A model for assessing the costs of stressors at national level: socio-economic costs of work stress in two EU member states. Dublin: European Foundation for the Improvement of Living and Working Conditions; 1996.

25. Bejean S, Sultan-Taïeb H: Modeling the economic burden of diseases imputable to stress at work. Eur J Health Econ 2005, 50(1):16-23.

26. LaMontagne AD, Sanderson K, Cocker F: Estimating the economic benefits of eliminating job strain as a risk factor for depression. Carlton, Australia: Victorian Health Promotion Foundation (VicHealth); 2010

27. Leigh JP: Expanding research on the economics of occupational health. Scand J Work Environ Health 2006, 32(1):1-4

28. Kivimäki M, Virtanen $M$, Elovainio $M$, Kouvonen A, Vaananen A, Vahtera J: Work stress in the etiology of coronary heart disease-a meta-analysis. Scand J Work Environ Health 2006, 32(6):431-442.

29. Belkic KL, Landsbergis PA, Schnall PL, Baker D: Is job strain a major source of cardiovascular disease risk? Scand J Work Environ Health 2004, 30(2):85-128.

30. Stansfeld S, Candy B: Psychosocial work environment and mental healtha meta-analytic review. Scand J Work Environ Health 2006, 32(6):443-462.

31. Bonde JP: Psychosocial factors at work and risk of depression: a systematic review of the epidemiological evidence. Occup Environ Med 2008, 65(7):438-445

32. Netterstrom B, Conrad N, Bech P, Fink P, Olsen O, Rugulies R, et al: The relation between work-related psychosocial factors and the development of depression. Epidemiol Rev 2008, 30:118-132

33. Bongers PM, ljmker S, Van den Heuvel S, Blatter BM: Epidemiology of work related neck and upper limb problems: psychosocial and personal risk factors (part I) and effective interventions from a bio behavioural perspective (part II). J Occup Rehabil 2006, 16(3):279-302

34. Sultan-Taieb H, Lejeune C, Drummond A, Niedhammer I: Fractions of cardiovascular diseases, mental disorders, and musculoskeletal disorders attributable to job strain. Int Arch Occup Environ Health 2011, 84(8):911-925.

35. Karasek R, Brisson C, Kawakami N, Houtman I, Bongers P, Amick B: The Job Content Questionnaire (JCQ): an instrument for internationally comparative assessments of psychosocial job characteristics. J Occup Health Psych 1998, 3(4):322-355.

36. Drummond M: Cost-of-illness studies: a major headache? Pharmacoeconomics 1992, 2(1):1-4

37. Drummond M, Sculpher M, Torrance G: Methods for the economic evaluation of health care programmes. 3rd edition. Oxford: Oxford University Press; 2005:379. xv.
38. Gold MR, Siegel JE, Russell LB, Weinstein MC: Cost-effectiveness in health and medicine. New York: Oxford University Press; 1996.

39. Byford S, Raftery J: Perspectives in economic evaluation. Bmj 1998, 316 (7143):1529-1530.

40. Torrance G, Blaker D, Detsky A, Kennedy W, Schubert F, Menon D, et al: Canadian Guidelines for Economic Evaluation of Pharmaceuticals. Pharmacoeconomics 1996, 9(6):535-559.

41. Levin ML: The occurrence of lung cancer in man. Acta Unio Int Contra Cancrum 1953, 9(3):531-541.

42. Niedhammer I, Chastang JF, Levy D, David S, Degioanni S, Theorell T: Study of the validity of a job-exposure matrix for psychosocial work factors: results from the national French SUMER survey. Int Arch Occup Environ Health 2008, 82(1):87-97.

43. Bosma H, Peter R, Siegrist J, Marmot M: Two alternative job stress models and the risk of coronary heart disease. Am J Public Health 1998, 88(1):68-74.

44. De Bacquer D, Pelfrene E, Clays E, Mak R, Moreau M, de Smet P, et al: Perceived job stress and incidence of coronary events: 3-year follow-up of the Belgian Job Stress Project cohort. Am J Epidemio/ 2005, 161(5):434-441.

45. Kivimäki M, Ferrie JE, Brunner E, Head J, Shipley MJ, Vahtera J, et al: Justice at work and reduced risk of coronary heart disease among employees: the Whitehall 2 Study. Arch Intern Med 2005, 165(19):2245-2251.

46. Kivimäki $M$, Theorell $T$, Westerlund $H$, Vahtera J, Alfredsson L: Job strain and ischaemic disease: does the inclusion of older employees in the cohort dilute the association? The WOLF Stockholm Study. J Epidemiol Community Health 2008, 62(4):372-374.

47. Kornitzer M, DeSmet P, Sans S, Dramaix M, Boulenguez C, DeBacker G, et al: Job stress and major coronary events: results from the Job Stress, Absenteeism and Coronary Heart Disease in Europe study. Eur J Cardiov Prev R 2006, 13(5):695-704. Oct.

48. Lee S, Colditz G, Berkman L, Kawachi I: A prospective study of job strain and coronary heart disease in US women. Int J Epidemiol 2002, 31(6):1147-1154.

49. Netterstrom B, Kristensen TS, Sjol A: Psychological job demands increase the risk of ischaemic heart disease: a 14-year cohort study of employed Danish men. Eur J Cardiov Prev R 2006, 13(3):414-420.

50. Orth-Gomer K, Wamala SP, Horsten M, Schenck-Gustafsson K, Schneiderman N, Mittleman MA: Marital stress worsens prognosis in women with coronary heart disease: The Stockholm Female Coronary Risk Study. Jama 2000, 284(23):3008-3014.

51. Uchiyama S, Kurasawa T, Sekizawa T, Nakatsuka H: Job strain and risk of cardiovascular events in treated hypertensive Japanese workers: hypertension follow-up group study. J Occup Health 2005, 47(2):102-111.

52. Bildt $\mathrm{C}$, Michelsen $\mathrm{H}$ : Gender differences in the effects from working conditions on mental health: a 4-year follow-up. Int Arch Occup Environ Health 2002, 75(4):252-258

53. Bourbonnais R, Comeau M, Vezina M: Job strain and evolution of mental health among nurses. J Occup Health Psychol 1999, 4(2):95-107.

54. Clays E, De Bacquer D, Leynen F, Kornitzer M, Kittel F, De Backer G: Job stress and depression symptoms in middle-aged workers-prospective results from the Belstress study. Scand J Work Environ Health 2007, 33(4):252-259.

55. Niedhammer I, Goldberg M, Leclerc A, Bugel I, David S: Psychosocial factors at work and subsequent depressive symptoms in the Gazel cohort. Scand J Work Environ Health 1998, 24(3):197-205.

56. Shields M: Long working hours and health. Health Rep 1999, 11(2):33-48.

57. Shields M: Stress and depression in the employed population. Health Rep 2006, 17(4):11-29.

58. Higgins JP, Thompson SG, Deeks JJ, Altman DG: Measuring inconsistency in meta-analyses. Bmj 2003, 327(7414):557-560.

59. Niedhammer I, Chastang JF, Gendrey L, David S, Degioanni S: Propriétés psychométriques de la version française des échelles de la demande psychologique, de la latitude décisionnelle et du soutien social du "Job Content Questionnaire" de Karasek: Résultats de l'enquête nationale SUMER. Sante Publique 2006, 18(3):413-427.

60. Niedhammer I, Chastang JF, David S: Importance of psychosocial work factors on general health outcomes in the national French SUMER survey. Occupational Medicine (London). 2008, 58(1):15-24

61. Niedhammer I, Chastang JF, David S, Kelleher C: The contribution of occupational factors to social inequalities in health: findings from the national French SUMER survey. Soc Sci Med 2008, 67(11):1870-1881.

62. Niedhammer I, Chastang J-F, Levy D, David S, Degioanni S: Exposition aux facteurs psychosociaux au travail du modèle de Karasek: étude 
méthodologique à l'aide de l'enquête nationale SUMER. Travailler. 2007, 17:47-70.

63. CEPIDC (Centre d'Épidémiologie sur les Causes Médicales de Décès): Interrogation des données sur les causes de décès de 1979 à 2010; 2003. [cited 2012]. Available from: http://www.cepidc.inserm.fr/inserm/html/ index 2.htm.

64. Isometsa E, Henriksson M, Marttunen M, Heikkinen M, Aro H, Kuoppasalmi K, et al: Mental disorders in young and middle aged men who commit suicide. Bmj 1995, 310(6991):1366-1367.

65. Bertolote JM, Fleischmann A, De Leo D, Wasserman D: Suicide and mental disorders: do we know enough? The British journal of psychiatry 2003, 183:382-383.

66. Michel G, Aquaviva E, Aubron V, Purper-Ouakil D: Suicides: mieux comprendre pour prévenir avec plus d'efficacité. In Baromètre santé 2005. Edited by Beck F, Guilbert P, Gautier A. Saint-Denis: Institut National de Prévention et d'Education pour la Santé, (INPES); 2007:p. 487-506.

67. Lepine JP, Gasquet I, Kovess V, Arbabzadeh-Bouchez S, Negre-Pages L, Nachbaur $\mathrm{G}$, et al: [Prevalence and comorbidity of psychiatric disorders in the French general population]. Encéphale 2005, 31(2):182-194. Mar-Apr.

68. Rice DP: Estimating the cost of illness. Am J Public Health 1967, 57(3):424-440.

69. Paris V, Renaud T, Sermet C: Des comptes de la santé par pathologie : un prototype pour l'année 1998. Paris: Centre de recherche d'étude et de documentation en économie de la santé (CREDES); 2003.

70. Fenina A, Geoffroy Y, Minc C, Renaud T, Sarlon E, Sermet C: Les dépenses de prévention et les dépenses de soins par pathologie en France. Questions d'Économie de la Santé. 2006, 111:1-8.

71. Eco-Santé France: Bases Eco-Santé France: IRDES (Institut de Recherche et Documentation en Économie de la Santé); 2003. [cited 2012]. Available from: http://www.irdes.fr/EcoSante/France.htm.

72. Morvan Y, Prieto A, Briffault X, Blanchet A, Dardennes R, Rouillon F, et al: La dépression: prévalence, facteurs associés et consommation de soins. In Baromètre santé 2005. Edited by Beck F, Guilbert P, Gautier A. Saint-Denis: Institut National de Prévention et d'Education pour la Santé (INPES); 2007:487-506.

73. De Peretti C, Chin F, Tuppin P, Danchin D: Personnes hospitalisées pour infarctus du myocarde en France: tendances 2002-2008. Bulletin Epidémiologique Hebdomadaire. 2012, 41:459-465.

74. Pérel C, Chin F, Tuppin P, Danchin D, Alla F, Juillière Y, et al: Taux de patients hospitalisés pour insuffisance cardiaque en 2008 et évolutions en 2002-2008, France. Bulletin Epidémiologique Hebdomadaire 2012 (41):466-470.

75. Siegrist J, Starke D, Chandola T, Godin I, Marmot M, Niedhammer I, et al: The measurement of effort-reward imbalance at work: European comparisons. Soc Sci Med 2004, 58(8):1483-1499.

76. LaMontagne AD, Keegel T, Louie AM AO: Job stress as a preventable upstream determinant of common mental disorders: A review for practitioners and policy-makers. Advances in Mental Health 2010, 9(1):17-35.

77. LaMontagne AD, Keegel T, Vallance D, Ostry A, Wolfe R: Job strain attributable depression in a sample of working Australians: assessing the contribution to health inequalities. BMC Publ Health 2008, 8:181.

78. LaMontagne AD, Keegel T, Louie AM, Ostry A, Landsbergis PA: A systematic review of the job-stress intervention evaluation literature, 1990-2005. Int J Occup Environ Health 2007, 13(3):268-280. Jul-Sep.

79. Egan M, Bambra C, Thomas S, Petticrew M, Whitehead M, Thomson H: The psychosocial and health effects of workplace reorganisation. 1. A systematic review of organisational-level interventions that aim to increase employee control. J Epidemiol Community Health 2007, 61(11):945-954

80. Bambra C, Egan M, Thomas S, Petticrew M, Whitehead M: The psychosocial and health effects of workplace reorganisation. 2. A systematic review of task restructuring interventions. J Epidemiol Community Health 2007, 61(12):1028-1037.

doi:10.1186/1471-2458-13-748

Cite this article as: Sultan-Taïeb et al:: The annual costs of cardiovascular diseases and mental disorders attributable to job strain in France. BMC Public Health 2013 13:748.

\section{Submit your next manuscript to BioMed Central and take full advantage of:}

- Convenient online submission

- Thorough peer review

- No space constraints or color figure charges

- Immediate publication on acceptance

- Inclusion in PubMed, CAS, Scopus and Google Scholar

- Research which is freely available for redistribution 